\title{
An Institutional Personal Learning Environment Enabler
}

\author{
Laurent Moccozet, Omar \\ Benkacem, Pierre-Yves Burgi \\ University of Geneva \\ Geneva, Switzerland \\ Laurent.Moccozet@unige.ch
}

\author{
Hervé Platteaux \\ Centre Nouvelles Technologies et \\ Enseignement \\ University of Fribourg \\ Fribourg, Switzerland \\ Herve.Platteaux@unifr.ch
}

\author{
Denis Gillet \\ School of Engineering \\ EPFL \\ Lausanne, Switzerland \\ Denis.Gillet@epfl.ch
}

\begin{abstract}
In this paper, we first discuss the concept of Personal Learning Environment (PLE) with respect to highereducation institutions and Virtual Learning Environments (VLEs). This discussion rapidly confronts us to the place of the PLE and self-directed learning and/or training inside the institution. We therefore introduce the concept of institutional PLE enabler, which is expected to stimulate students to create and use their own resources and institutional resources and share them with peers during formal and informal learning activities. Next, we describe a proposal for a federated design and implementation of the PLE enabler across multiple institutions.
\end{abstract}

Personal learning environment; virtual learning environment; self-directed learning; Web 2.0

\section{INTRODUCTION}

Virtual Learning Environments (VLEs) involve a variety of tools, which generally share the feature of being institutionally controlled. To respond to the trend of learners increasingly consuming web tools and sharing contents within the cloud, the concept of institutional PLE enabler, built on recent student-centric approaches is first presented, along with a concrete implementation.

\section{A. Virtual Learning Environments and Beyond}

In higher education, Information and Communication Technology (ICT) based Learning Environments (LEs) are actually widely established. Nowadays it is common that higher education institutions provide teaching and learning through some kind of VLEs. This is confirmed for Switzerland where all institutions are equipped with at least one VLE [1]. From a pedagogical point of view, in the way VLEs are designed and implemented, they favour and induce the traditional form of academic face-to-face teaching with a predominantly teacher-centric form, although some evolutions are currently emerging.

As a counterpart to VLEs, which are often marked as institutional [3], a new concept has recently emerged: the Personal Learning Environment (PLE). Innovative teaching and learning concepts are readily introduced in PLEs, requiring specific technology infrastructures, which may not necessarily exist yet. The concepts behind PLEs are not yet clearly identified, as exemplified by the numerous definitions available from literature [2] [3] [4] [5]. More concretely, in
[3] the PLE is considered as the set of all resources that learners are using, even including their mental resources (i.e., models, tools, and knowledge). The PLE is therefore part of the "person-plus" [7] concept, which takes into account the learners' physical and social surrounds in addition to themselves. It is also closely related to the introduction of the Web 2.0 ecosystem in learning activities [8].

\section{B. Bridging Institutional and Personal Learning Environments}

Although VLEs are usually presented in opposition to PLEs, they cannot be simply excluded from the learning environment landscape or replaced by PLEs. To some extent, the VLEs, as used by learners for their learning activities, should also be considered as one of the many components of their PLEs. Usually, VLEs provide learning objectives, deliver learning resources and propose validated testing activities. Such support is essential for individual learners with limited autonomy.

Reference [3] expresses well the various possible viewpoints with respect to the double pairs VLEs/institutions PLEs/students: “... whether PLEs should remain the sole domain of the learner, or whether in some way they could be incorporated into institutional infrastructures". These positions are still debatable and no global agreement has emerged yet. According to [9], institutions should provide two distinct but related environments: an Informal LE to support the learning process based on self-paced contents and features and a Formal LE to manage learning with features akin to VLEs. In [3], the PLE design is augmented with a Cloud LE presented as a conceptual bridge between the personal web tools of the PLE and the institutional VLE. The concept of "institutional PLE" is proposed in [10]: it is defined as "an environment that provides a personalised interface to University data and services and at the same time exposes that data and services to a student's personal tool". Another alternative is depicted in [2]: first, the iPLE consists in providing some Web 2.0 tools inside the VLE, and second, the Hybrid Institutional PLE (HIPLE) allows the direct use of third parties Web 2.0 tools.

The aim of this paper is to further develop the notion of Institutional PLE, which represents a powerful concept helping to establish a bridge between VLE and PLE hosted 
by third parties. We argue that the main issue is finally not to provide an institutional PLE but rather an extension of the PLE itself: a "PLE enabler". Such a PLE enabler aims to bridge personal, institutional and worldwide resources, as well as to enable collaborations between co-learners and sharing of resources. It therefore provides a unique framework merging learning services and features offered by iPLE and HIPLE. The resulting scheme can be viewed as a student centric self-directed collaborative didactic dashboard, clearly distinct from a VLE. In this view, the role of the didactic dashboard is key to provide an ergonomic interface to learners who can manage with ease their didactic personal resources (from their own PWT), the institutional resources (from the VLE) and work by interacting with them. The PLE enabler is thus a kind of "meta" or "augmented" PLE behaving like a didactic hub in which three components are further added: collaboration with peers, digital literacy training resources and recommendations obtained from a recommendation engine.

\section{PLE ENABLER DESIGN}

In this section, the main components of the proposed institutional PLE enabler are described more concretely. Considering that a PLE is closely related to life-long learning and students' mobility (student are not bounded to a single institution), our proposal further integrates a quite new dimension: the federation of institutions which we test in the three Swiss institutions: the Universities of Fribourg and Geneva and the Swiss Federal Institute of Technology in Lausanne. Working within a federation asks for an adaptive and flexible design that can be deployed within different preexisting LEs, such as Learning Management Systems and ePortfolios, while keeping a common and consistent framework. This federated approach also enables a resource recommendation engine to work inter-institutionally, benefiting from the aggregation of a larger set of recommended resources (coming from each institution), visible to the learners through their dashboard widgets.

Our initial implementation of the PLE relies on the Graasp social media platform (formally called Graasp) [11]. Graasp's main purpose is to support self-directed learners and knowledge workers in their daily online learning and knowledge management practices. Graasp enables the aggregation, the sharing and the interaction with a rich set of resources in private and public contexts defined by the learners themselves, and is based on the so-called $3 \mathrm{~A}$ interaction model [12]. To stimulate collaboration and cooperation between learners, activities and assets are both declared as public by default. To enforce self-directed learning, and in strong opposition with traditional VLEs, all users have the same role giving them access to exactly the same functions. This feature introduces a new relationship between teachers and students and unlocks new scenarios: a student inviting peers to a learning activity, or a student inviting teachers to a learning activity.

While the potential of such framework to bridge formal and informal learning is real, such potential will not be fully expressed as long as the obstacles inherently related to inherited learning habits have not been overpassed.

\section{ACKNOWLEDGEMENTS}

This PLE project (ple.unige.ch) is supported by the Swiss Innovation and Cooperation 2008-2012 program - in the AAA/SWITCH e-Infrastructure for e-Science project (www.switch.ch/aaa/). The development of Graasp as a PLE enabler is partially supported through the EU ICT FP7 ROLE project.

\section{REFERENCES}

[1] SWITCH, "LMS installations 2010 at swiss institutions of higher education", EduHub, retrieved December 11, 2011 from http://www.eduhub.ch/info/lms-installations10.html, October 2010.

[2] I. Peña-López, "Mapping the PLE-sphere”, ICTlogy, \#82, Barcelona: ICTlogy, retrieved December 11, 2011 from http://ictlogy.net/review/?p=3437, July 2010.

[3] S. Wheeler, "Anatomy of a PLE", Learning with "e"s , Plymouth:Learning with 'e's, retrieved December 11, 2011 from http://steve-wheeler.blogspot.com/2010/07/ anatomy-of-ple.html, July 2010 .

[4] G. Attwell Graham, "Personal learning environments - the future of eLearning?", eLearning Papers, Vol. 2, ISSN 1887-1542, January 2007.

[5] T. Valtonen, S. Hacklin, P. Dillon, M. Vesisenaho, J. Kukkonen, and A. Hietanen, "Perspectives on personal learning environments held by vocational students", Computers \& Education, vol. 58, févr. 2012, pp. 732-739, doi:10.1016/j.compedu.2011.09.025.

[6] N. Sclater, "Web 2.0, personal learning environments and the future of learning management systems", Educause Center for Applied Research, Research Bulletin, Boulder, Colorado, http://oro.open.ac.uk/16304/, 2008.

[7] D. N. Perkins, « L'individu-plus. Une vision distribuée de la pensée et de l'apprentissage », Revue française de pédagogie, 111(1), pp. 57-71, 1995.

[8] Moccozet, L., "Personal information ecosystem: A framework for immersive blended training in information and communication technologies literacy," Proc. 3rd IEEE International Conference on Digital Ecosystems and Technologies (DEST 09), IEEE Press, 1-3 June 2009, pp.229-234, doi:10.1109/DEST.2009.5276784.

[9] R. Tracey, "The ILE and FLE in harmony", E-learning provocateur, $\begin{array}{llll}\text { retrieved } & \text { December } & 11, & 2011\end{array}$ http://ryan2point0.wordpress.com/2010/07/15/the-ile-and-the-fle-inharmony/, July 2010.

[10] D. E. Millard, H. C. Davis, Y. Howard, P. McSweeney, C. Yorke, H. Solheim, and D. Morris, "Towards an institutional PLE", Proc. Personal Learning Environment Conference 2011 (PLE’2011), pp. 114, Southampton, UK, July 2011.

[11] E. Bogdanov, S. El Helou, D. Gillet, C. Salzmann, and S. Sire, "Graaasp: a web 2.0 research platform for contextual recommendation with aggregated data", Proc. 28th of the International Conference extended abstracts on Human factors in computing systems (CHI EA '10). ACM, New York, NY, USA, pp. 3523-3528, doi:10.1145/1753846.1754012.

[12] S. El Helou, L. Na, D. Gillet, "The 3A Interaction Model: Towards Bridging the Gap between Formal and Informal Learning," Proc. Third International Conference on Advances in Computer-Human Interactions (ACHI 10), IEEE Press, 10-15 Feb. 2010, pp.179-184, doi: 10.1109/ACHI.2010.38. 